\title{
A call for Effective Interventions to Curb Shisha Tobacco Smoking among University Students in Eastern Province, Saudi Arabia: Findings from a Cross-Sectional Study
}

\author{
Dhfer Alshayban, Royes Joseph*
}

\begin{abstract}
Background: Although the number of cigarettes smoked has been declining due to major public health initiatives, shisha tobacco smoking is gaining popularity around the world, particularly among youth and university students. Methods: A cross-sectional study was conducted among 464 university students in Eastern Province of Saudi Arabia using a structured questionnaire (i) to assess the prevalence of shisha smoking; (ii) to evaluate risk-perception, knowledge and normative belief about shisha smoking, and to compare these among users and non-users of shisha. Results: The study reported a high prevalence $(22.8 \%)$ of the current use of shisha among the university students with a narrow gender gap and found that STS is getting more popular than other forms of tobacco. A quarter of participants had low risk perception and 30.2\% had low knowledge of shisha smoking harm. Importantly, more than two-fifth of them were current users of shisha. Low risk-perception about shisha and social acceptability were significantly contributed to the high prevalence of shisha smoking among the youth. Conclusion: It is important to provide exposure to education related to shisha hazards and increase the awareness of students and the public about the health effects of shisha smoking.
\end{abstract}

Keywords: Smoking water pipes- prevalence- knowledge- universities- Saudi Arabia

Asian Pac J Cancer Prev, 20 (10), 2971-2977

\section{Introduction}

Tobacco use appears to be increasing in the African and Eastern Mediterranean Regions (World Health Organization, 2015). According to the Tobacco Atlas, more than 20,000 children (10-14 years old) and 3.35 million adults ( $15+$ years old) continue to use tobacco daily in Saudi Arabia, and more than 7,000 deaths occur every year due to tobacco-caused diseases in the country (Drope et al., 2018). Although the number of cigarettes smoked has been declining due to major public health initiatives (Drope et al., 2018), shisha (also referred to as waterpipe, Hookah, Narghile, or Arghile) tobacco smoking (STS) is gaining popularity in the Eastern Mediterranean Region, with no exemption to Saudi Arabia, and around the world, particularly among youth and university students (Maziak, 2011; Naeem, 2011; Akl et al., 2015; Jawad et al., 2018). The latest Saudi Arabia global youth tobacco survey of students aged 13-15 years, which was conducted in 2010, reported that $9.5 \%$ of students were current smokers of shisha (Centers for Disease Control and Prevention, 2010). The reports of regional surveys at this period indicated that the prevalence of shisha use ranged from 13\%-33\% among high school and university students (Amin et al., 2010; Taha et al., 2010; Naeem, 2011; Al Moamary et al.,
2012; Jradi and Al-Shehri, 2014; AlSwuailem et al., 2014) in the central and eastern Saudi Arabia. A notable increase in shisha use has been reported recently from the central and the western regions (Awan et al., 2016; Al Ghobain et al., 2018; Daradka et al., 2019), but no such estimate is available from the eastern region of Saudi Arabia.

Studies have been conducted on the risk associated with STS including its health effects, the addictive potential and the cross infection risk of sharing shisha mouthpiece (Eissenberg and Shihadeh, 2009; Aslam et al., 2014; WHO Study Group on Tobacco Product Regulation, 2015; Aboaziza and Eissenberg, 2015; Maziak et al., 2015b; Primack et al., 2016; Waziry et al., 2016). The studies suggest that shisha smokers may inhale a larger volume of smoke than cigarette smokers in a single session, and no or very little nicotine filtered out when the smoke passes through the water-filled chamber of shisha device (Primack et al., 2016). These studies concluded that STS has the health risks that are associated with cigarette smoking, including addiction (Aboaziza and Eissenberg, 2015). Evidence showed that STS is associated with many diseases including lung, gastric and oesophageal cancer, heart and lung diseases, periodontal disease, and low birth weight (Waziry et al., 2016). A cross-sectional study (2015) of male students from a university in the central 
region of Saudi Arabia reported that knowledge about the health hazards of STS was low among the students (Awan et al., 2016). Studies from neighboring countries of Saudi Arabia, which were conducted among young shisha users, observed that a substantial proportion of the shisha users viewed shisha as a safer alternative to cigarettes (Jaam et al., 2016; Abu-Rmeileh et al., 2018). Lack of effective interventions that target young population, who smoke shisha, is a serious public health concern in Saudi Arabia (Maziak et al., 2015a).

World Health Organization Study Group on Tobacco Product Regulation calls for more research on all aspects of STS including the types and patterns of STS in all regions and cultures (WHO Study Group on Tobacco Product Regulation, 2015). The objectives of this study were (i) to assess the prevalence of STS and its predictors among the university students in Eastern Province of Saudi Arabia; and (ii) to evaluate risk-perception, knowledge and normative belief about STS, and compared these among users and non-users of STS.

\section{Materials and Methods}

\section{Study design and participants}

A cross-sectional study was conducted among the undergraduate students during March-May 2018. A minimum sample size of 323 was calculated to estimate a prevalence rate of $30 \%$ with the absolute precision of 0.05 and $95 \%$ confidence level. We targeted a sample of 500 students from the colleges of Imam Abdulrahman Bin Faisal University (IAU), Saudi Arabia which is one of the leading public universities in the Eastern Region. A group of three final year students from the university were recruited and trained for data collection using the study questionnaire. The group approached other students in public places, such as atrium, café and library, within the colleges, and requested them to fill the questionnaire. The participants were informed about the aim of the study and data collectors' availability for clarifications on the questionnaire items. Informed consent was obtained from each participant before they participate in the study, and the study was approved by the research and ethics committee of the IAU.

\section{Questionnaire}

The survey instrument was developed, in Arabic, from a literature review and questions adapted from previously published STS studies (Primack et al., 2008). The first section was about socio-demographics details such as age, gender, study stream, residence location (urban/rural), marital status (single/married), and family monthly income. The second section was intended to assess the prevalence of smoking shisha, cigarettes and e-cigarettes. The participants were asked if they had smoked these forms of tobacco within the past one year (for 12-month prevalence) and within the past 30 days (for 30-day prevalence). They were also asked to report how frequent their family members or friends use STS.

The third section consisted of two questions related to risk-perception about STS where the participants were asked to rate harmfulness and addictiveness of STS compared to cigarettes on a five-point scale ranging from 'STS is much less harmful/addictive' with score of ' 0 'to STS is much more harmful/addictive with score of '4'. A summary risk-perception score was calculated by adding these scores, and it ranges from 0 to 8 with the low score represents high false perception about STS. The next section included five items related to knowledge of STS-related hazards: the level of knowledge was assessed based on the ability of students to recognize the toxic contents of STS (water filtering of toxins; absence of tar, nicotine and carbon monoxide) and to identify diseases associated with STS (no increased risk of cardiovascular diseases [CVD]). The responses to these items were obtained on a 5-point Likert scale with score ranges from 0 for strongly agree to 4 for strongly disagree. A summary knowledge score was computed, and the summative score can be ranged from 0 to 20 with the higher the score represents the higher knowledge about the health effects of STS. Finally, to measure the normative beliefs, the participants were asked to rate the social acceptance of STS in the society. The response scale included "not acceptable", "somewhat acceptable", "moderately acceptable", and "very acceptable".

\section{Analysis}

The past 30-day and past 12-month users were defined as those who smoked at least one time in the previous 30 days and previous 12 months respectively. Past 30-day use of STS was considered the primary outcome. The responses to items in risk-perception and knowledge factors were collapsed into three categories for the analysis purpose. Additionally, the risk-perception and knowledge scores were also collapsed into tertiles, which represent the categories low score (highly favored for shisha), moderate score and high score (less favored for shisha).

Data were presented as frequencies and percentages. Univariate analysis using chi-square statistics was initially carried out test the association between past 30-day use of STS and predictor variables. Predicator variables include socio-demographic characteristics, smoking behavior, risk-perception score, knowledge score, and social acceptance rating. Odds ratios and $95 \%$ confidence intervals were then derived using multiple logistic regression, adjusting the predictor variables that found statistically significant in the univariate analysis. For all analyses, a p-value less than 0.05 (two-sided) indicated statistical significance. Statistical analyses were conducted using SPSS Statistics (version 24.0).

\section{Results}

\section{Socio-demographic information}

The study questionnaires were filled by 464 university students with a response rate of $92.8 \%$. Table 1 , in the second column, summarizes the socio-demographic characteristics of participants. The mean (SD) age was 20.7 (1.3) years, and $64.7 \%$ of participants were from health stream. The sample comprised of more male students, and with equal representation of participants from different income levels. 
DOI:10.31557/APJCP.2019.20.10.2971

Shisha Smoking among University Students

Table 1. Socio-Semographics and Shisha Tobacco Smoking $(\mathrm{N}=464)$

\begin{tabular}{|c|c|c|c|}
\hline \multirow[t]{2}{*}{ Factors } & \multirow{2}{*}{$\begin{array}{l}\text { Total } \\
\text { n (\%) }\end{array}$} & \multicolumn{2}{|c|}{ Shisha used within 30 days } \\
\hline & & $\mathrm{n}(\%)$ & p-value ${ }^{1}$ \\
\hline \multicolumn{4}{|l|}{ Gender } \\
\hline Male & $268(57.8 \%)$ & $68(25.4 \%)$ & 0.129 \\
\hline Female & $196(42.2 \%)$ & $38(19.4 \%)$ & \\
\hline \multicolumn{4}{|l|}{ Area of study } \\
\hline Health & $300(64.7 \%)$ & $70(23.3 \%)$ & 0.895 \\
\hline Engineering & $78(16.8 \%)$ & $18(23.1 \%)$ & \\
\hline $\begin{array}{l}\text { Arts, Science and } \\
\text { Management }\end{array}$ & $86(18.5 \%)$ & $18(20.9 \%)$ & \\
\hline \multicolumn{4}{|l|}{ Locality } \\
\hline Urban & $378(81.5 \%)$ & $98(25.9 \%)$ & $0.001 *$ \\
\hline Rural & $86(18.5 \%)$ & $8(9.3 \%)$ & \\
\hline \multicolumn{4}{|l|}{ Marital status } \\
\hline Single & $436(94 \%)$ & $100(22.9 \%)$ & 0.854 \\
\hline Married & $28(6 \%)$ & $6(21.4 \%)$ & \\
\hline \multicolumn{4}{|l|}{ Family monthly income } \\
\hline Less than 5,000 SR & $74(15.9 \%)$ & $12(16.2 \%)$ & 0.063 \\
\hline $5,000-15,000$ & $142(30.6 \%)$ & $24(16.9 \%)$ & \\
\hline $16,000-25,000$ & $154(33.2 \%)$ & $48(31.2 \%)$ & \\
\hline Greater than 25,000 & $94(20.3 \%)$ & $22(23.4 \%)$ & \\
\hline
\end{tabular}

${ }^{1}$ Chi-square test was carried out; *statistically significant

Prevalence of smoking: shisha, cigarettes, and e-cigarettes

Figure 1 presents the past 12-month and 30-day prevalence (with 95\% confidence interval) of smoking shisha, cigarettes and e-cigarettes. The self-reported past 12-month and 30-day prevalence of STS were $29.3 \%$ and $22.8 \%$, respectively. The prevalence of shisha smoking was slightly higher than that of cigarettes smoking and noticeably higher than that of e-cigarettes smoking among the participants.

Table 1 presents the past 30-day STS status among the socio-demographic levels. Importantly, no significant difference in prevalence of STS between male and female students was observed, though the proportion was slightly higher among male students (25.4\% vs. $19.4 \%$; $\mathrm{p}$-value $=0.129)$. The table shows that urban students
Table 2. Cigarette Smoking and Shisha Tobacco Smoking $(\mathrm{N}=464)$

\begin{tabular}{lccc}
\hline \multicolumn{2}{c}{ Total } & \multicolumn{2}{c}{ Shisha used within 30 days $^{2}$} \\
n (\%) & n (\%) & p-value ${ }^{1}$ \\
\hline Cigarettes used within 12 months & & \\
No & $352(75.9 \%)$ & $42(11.9 \%)$ & $<0.001^{*}$ \\
Yes & $112(24.1 \%)$ & $64(57.1 \%)$ & \\
Cigarettes used within 30 days & & \\
No & $362(78 \%)$ & $46(12.7 \%)$ & $<0.001^{*}$ \\
Yes & $102(22 \%)$ & $60(58.8 \%)$ & \\
e-cigarettes used within 12 months & & \\
No & $360(77.6 \%)$ & $48(13.3 \%)$ & $<0.001^{*}$ \\
Yes & $104(22.4 \%)$ & $58(55.8 \%)$ & \\
e-cigarettes used within 30 days & & \\
No & $392(84.5 \%)$ & $62(15.8 \%)$ & $<0.001^{*}$ \\
Yes & $72(15.5 \%)$ & $44(61.1 \%)$ & \\
Use of Shisha by family/friends & & \\
Never used & $168(36.2 \%)$ & $16(9.5 \%)$ & $<0.001^{*}$ \\
Rarely used & $94(20.3 \%)$ & $18(19.1 \%)$ & \\
Occasionally used & $90(19.4 \%)$ & $26(28.9 \%)$ & \\
Frequently used & $112(24.1 \%)$ & $46(41.1 \%)$ & \\
\hline
\end{tabular}

Chi-square test was carried out; *statistically significant

were more prone to STS compared to rural students ( $25.9 \%$ vs. $9.3 \%$; p-value $=0.001)$. There was no difference in prevalence of STS between levels of study stream, marital status, or family income ( $p$-value $>0.05$ ).

Table 2 presents the past 30 -day STS status among users of cigarette and e-cigarette. The past 30-day shisha use was significantly associated with the cigarette/e-cigarette use and the use of shisha among the family members or friends (p-value $<0.001)$.

STS-related risk-perception, knowledge and normative beliefs

Table 3 presents STS-related risk-perception, knowledge and normative beliefs among the participants, in overall and by past 30-day STS status.

Regarding the risk-perception, $38.4 \%$ and $44.0 \%$ of participants answered that STS is less harmful and less

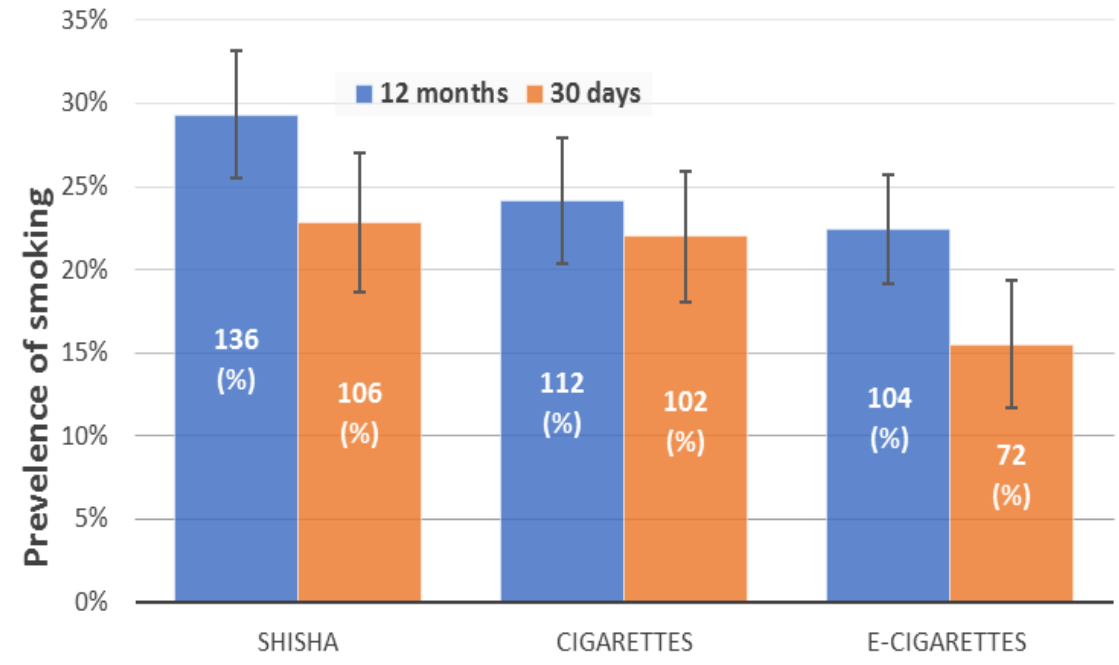

Figure 1. Past 12-month and 30-day Prevalence of Smoking. The vertical line represents the 95\% confidence interval. 
addictive, respectively, compared to cigarette smoking. Importantly, significantly higher past 30-day STS prevalence was reported among these groups compared to others. Thus, in combined, $43.1 \%$ of participants with low risk-perception score were shisha user in the past 30 days compared to the prevalence of $7.3 \%$ among participants with a high risk-perception score ( $p$-value $<0.001$ ).

Regarding the STS-related knowledge, a substantial

Table 3. Prevalence of Past 30-Day STS, and STS-Related Risk-Perception, Knowledge and Normative Beliefs among the University Students $(\mathrm{N}=464)$

\begin{tabular}{|c|c|c|c|}
\hline \multirow[t]{2}{*}{ Factors } & \multirow{2}{*}{$\begin{array}{l}\text { Total } \\
\text { n }(\%)\end{array}$} & \multicolumn{2}{|c|}{$\begin{array}{c}\text { Shisha used within } \\
30 \text { days }\end{array}$} \\
\hline & & $\mathrm{n}(\%)$ & p-value \\
\hline \multicolumn{4}{|c|}{ Belief about harmfulness compared to Cigarettes } \\
\hline Shisha is more harmful & $140(30.2)$ & $20(14.3)$ & $<0.001 *$ \\
\hline Shisha is equally harmful & $146(31.5)$ & $20(13.7)$ & \\
\hline Shisha is less harmful & $178(38.4)$ & $66(37.1)$ & \\
\hline \multicolumn{4}{|l|}{ Belief about addictiveness } \\
\hline Shisha is more Addictive & $152(32.8)$ & $22(14.5)$ & $<0.001^{*}$ \\
\hline Shisha is equally Addictive & $108(23.3)$ & $14(13.0)$ & \\
\hline Shisha is less Addictive & $204(44.0)$ & $70(34.3)$ & \\
\hline \multicolumn{4}{|l|}{ Risk-perception score (overall) } \\
\hline Low (highly favoured for shisha) & $116(25.0)$ & $50(43.1)$ & $<0.001 *$ \\
\hline Moderate & $238(51.3)$ & $48(20.2)$ & \\
\hline High (Less favoured for shisha) & $110(23.7)$ & $8(7.3)$ & \\
\hline \multicolumn{4}{|l|}{ Belief about water filtering of toxins } \\
\hline Completely/̋ Substantially & $120(25.9)$ & $48(40.0)$ & $<0.001^{*}$ \\
\hline Moderately & $218(47.0)$ & $46(21.1)$ & \\
\hline Slightly/Nothing & $126(27.2)$ & $12(9.5)$ & \\
\hline \multicolumn{4}{|l|}{ Belief about absence of tar } \\
\hline Agree & $240(51.7)$ & $72(30)$ & $<0.001^{*}$ \\
\hline Neutral & $70(15.1)$ & $16(22.9)$ & \\
\hline Disagree & $154(33.2)$ & $18(11.7)$ & \\
\hline \multicolumn{4}{|l|}{ Belief about absence of nicotine } \\
\hline Agree & $204(44.0)$ & $64(31.4)$ & $<0.001 *$ \\
\hline Neutral & $80(17.2)$ & $26(32.5)$ & \\
\hline Disagree & $180(38.8)$ & $16(8.9)$ & \\
\hline \multicolumn{4}{|c|}{ Belief about absence of carbon monoxide } \\
\hline Agree & $210(45.3)$ & $68(32.4)$ & $<0.001 *$ \\
\hline Neutral & $46(9.9)$ & $14(30.4)$ & \\
\hline Disagree & $208(44.8)$ & $24(11.5)$ & \\
\hline \multicolumn{4}{|l|}{ Belief about increased risk of CVD } \\
\hline Disagree & $132(28.4)$ & $62(47)$ & $<0.001$ \\
\hline Neutral & $72(15.5)$ & $18(25)$ & \\
\hline Agree & $260(56)$ & $26(10)$ & \\
\hline \multicolumn{4}{|l|}{ Knowledge score (overall) } \\
\hline Low (highly favoured for shisha) & $140(30.2)$ & $58(41.4)$ & $<0.001$ \\
\hline Moderate & $170(36.6)$ & $32(18.8)$ & \\
\hline High (Less favoured for shisha) & $154(33.2)$ & $16(10.4)$ & \\
\hline \multicolumn{4}{|l|}{ Normative belief (Social acceptance) } \\
\hline Not acceptable & $146(31.5)$ & $14(9.6)$ & $<0.001 *$ \\
\hline Somewhat acceptable & $152(32.8)$ & $32(21.1)$ & \\
\hline Moderately acceptable & $100(21.6)$ & $34(34.0)$ & \\
\hline Very acceptable & $66(14.2)$ & $26(39.4)$ & \\
\hline
\end{tabular}

${ }^{1}$ Chi-square test was carried out; *statistically significant proportion of participants believed that water filters toxins substantially or completely $(25.9 \%)$, STS is free of tar $(51.7 \%)$, nicotine $(44.0 \%)$ or carbon monoxide $(45.3 \%)$, and disagreed with the increased risk of CVD (28.4\%). A significant proportion $(30.0 \%-47.0 \%)$ of them had used shisha in the past 30 days. Thus, in overall, $41.4 \%$ of participants with low knowledge score were shisha user in the past 30 days compared to the prevalence of $10.4 \%$ among participants with high knowledge score (p-value $<0.001$ ).

Of the sample, $35.8 \%$ considered STS as "moderatelyvery socially acceptable". The prevalence of STS was significantly higher in these groups $(34.0 \%-39.4 \%)$ compared to the contrary groups $(9.6 \%-21.1 \%$; p-value $<0.001)$.

\section{Multivariable model}

In a fully adjusted multivariable logistic model (Table 4), past 30-day STS was significantly associated with both cigarette and e-cigarette use, urban status, low perceived risk, and belief about the social acceptance. The level of knowledge was not significantly associated with the current use of STS after adjusted for other factors, particularly the level of risk-perception.

Table 4. Multivariable Logistic Model for 30-day STS $(\mathrm{N}=464)$

\begin{tabular}{|c|c|c|}
\hline Factors & AOR $(95 \% \mathrm{CI})$ & p-value \\
\hline \multicolumn{3}{|l|}{ Locality } \\
\hline Urban & $6.28(2.11-18.69)$ & $0.001 *$ \\
\hline Rural & Reference & \\
\hline \multicolumn{3}{|l|}{ Cigarettes used within 12 months } \\
\hline No & Reference & \\
\hline Yes & $5.44(2.94-10.05)$ & $<0.001^{*}$ \\
\hline \multicolumn{3}{|l|}{ e-cigarettes used within 12 months } \\
\hline No & Reference & \\
\hline Yes & $4.86(2.57-9.21)$ & $0.001 *$ \\
\hline \multicolumn{3}{|l|}{ Use of Shisha by family } \\
\hline Never used & Reference & \\
\hline Rarely used & $1.91(0.8-4.58)$ & 0.146 \\
\hline Occasionally used & $2.78(1.13-6.81)$ & $0.025^{*}$ \\
\hline Frequently used & $2.97(1.32-6.68)$ & $0.008^{*}$ \\
\hline \multicolumn{3}{|l|}{ Risk-perception score (overall) } \\
\hline Low (highly favoured for shisha) & $6.89(1.94-24.47)$ & $0.003 *$ \\
\hline Moderate & $2.21(0.72-6.82)$ & 0.169 \\
\hline High (Less favoured for shisha) & Reference & \\
\hline \multicolumn{3}{|l|}{ Knowledge score (overall) } \\
\hline Low (highly favoured for shisha) & $1.43(0.55-3.72)$ & 0.464 \\
\hline Moderate & $0.83(0.33-2.13)$ & 0.702 \\
\hline High (Less favoured for shisha) & Reference & \\
\hline \multicolumn{3}{|l|}{ Normative belief (Social acceptance) } \\
\hline Not acceptable & Reference & \\
\hline Somewhat acceptable & $2.6(1.1-6.14)$ & $0.029 *$ \\
\hline Moderately acceptable & $4.9(2.05-11.73)$ & $<0.001^{*}$ \\
\hline Very acceptable & $5.48(2.1-14.28)$ & $0.001 *$ \\
\hline
\end{tabular}

AOR, adjusted odds ratio; CI, Confidence interval; *statistically significant 


\section{Discussion}

The present cross-sectional study assessed the prevalence of STS among university students based on a sample from the colleges of a leading university in Eastern Region, Saudi Arabia. The study also evaluated risk-perception, knowledge and normative belief about STS among the university students, and compared these among users and non-users of STS. Our study shows that the past 30-day and 12-month prevalence of STS among university students were $22.8 \%$ and $29.3 \%$, respectively. The prevalence of STS from the study was substantially higher than the prevalence of $12.6 \%$ which had reported in 2008 among a sample from the same university (Taha et al., 2010); the finding indicates a noticeable increase in shisha use over the time. Similarly, a high prevalence of STS among students was also reported from universities in Al Madinah and Riyadh regions of Saudi Arabia (Awan et al., 2016; Daradka et al., 2019), in other countries in the Eastern Mediterranean Region (Roohafza et al., 2015; Jaam et al., 2016; Tucktuck et al., 2018). The current estimate was also higher than that among the general adult population in Saudi Arabia (Al Nomay and $\mathrm{E}$ Ahmed, 2015). A recent study among physicians in Riyadh, Saudi Arabia showed a high prevalence of past 30 -day use of STS (45\%), and the highest prevalence was reported among newly graduated trainees (Al Ghobain et al., 2018). The availability of flavored tobacco, the thriving coffee shop culture and the limited regulations boost the spread of STS globally (Maziak et al., 2015b). The findings reflect an emerging STS epidemic among youth in Saudi Arabia and other countries in the Eastern Mediterranean Region.

Although the prevalence of cigarette smoking was relatively higher among males in Saudi Arabia (Algabbani et al., 2018), our study reported a high prevalence of STS among males and female students with a narrow gender gap in consistent with a recent study from the western region of Saudi Arabia (Daradka et al., 2019). A national survey on tobacco use among individuals aged 15 years or older in Saudi Arabia also reported a substantially lower female-male ratio on the prevalence of daily STS compared to that of daily use of all forms of tobacco (Moradi-Lakeh et al., 2015).

Importantly, along with other studies in the Eastern Mediterranean Region (Roohafza et al., 2015; Tucktuck et al., 2018), our study found that the prevalence of STS had surpassed that of cigarette or e-cigarette smoking. The recent study from the western region of Saudi Arabia reported that the prevalence of shisha smoking did not relatively differ from that of cigarettes smoking (Daradka et al., 2019). Further, the present study observed that more than half of the current cigarette or e-cigarette smokers were current shisha smokers, whereas, no more than $16 \%$ of non-users of other forms of tobacco were current shisha smokers. These findings indicate that STS has increasing popularity and is getting more common than cigarettes or e-cigarettes smoking among youth in both genders. The current study also found that substantially higher prevalence of STS among the participants whose close family members or friends were frequent users of shisha or the participants who believed STS is socially well acceptable. The findings support an argument that socio-cultural norms towards STS far outweighed its health impacts (Afifi et al., 2013).

Many people have a misconception that STS is a safer alternative to cigarette smoking. A recent study that had been conducted among the ever users of STS in the five neighboring countries reported that $44 \%$ of users believed STS is less addictive than cigarette smoking with the highest of 54\% among Egyptian users (Abu-Rmeileh et al., 2018); in our study, this estimate was $66 \%$ of past-30 day users. A similar pattern was observed regarding the belief about the harmfulness of STS. In overall, according to the multiple logistic model in the current study, those with low risk-perception about STS had more than seven times the odds of being a past 30-day shisha user compared with those with high risk-perception about STS. Despite of evidence for the harmful and addictive effects (Aslam et al., 2014; Aboaziza and Eissenberg, 2015; Primack et al., 2016), STS is often used as a safe alternative of cigarette smoking probably due to the misconception.

The misconception about the harmful and addictive effects of STS is linked with the lack of awareness of the health effects of STS (Salloum et al., 2017). Researchers have demonstrated that one session of STS was associated with more than 100 times volume of smoke inhalation and higher levels of nicotine, tar and carbon monoxide compared with one cigarette, in contrast to the misconception that water used in the pipe absorbs toxic elements (Primack et al., 2016). In the current study, nearly three-fourths of the participating students believed that the water used in the pipe moderately or substantially removes the toxic elements. In particular, 52\%, 44\% and $45 \%$ believed STS to be safe from tar, nicotine and carbon monoxide respectively. Further, $28 \%$ were failed to recognize STS as a risk factor for CVD. Importantly, a substantial proportion of these students were current shisha users. The multivariate model showed that the overall knowledge score was not a significant independent predictor of current shisha use, whereas the risk-perception was a significant predictor. Studies have reported that knowledge is positively associated with risk-perception (Allen and Butler, 1993). Thus, the ignorance of the health effects of STS is a major concern, and it is important to provide exposure to education related to STS hazards and increase the awareness of students and public about the health effects of STS.

Some limitations should be noted. The study was conducted among a convenient sample of undergraduate students from a university in the Eastern Province, Saudi Arabia. However, the selection of the sample from different colleges within the university and the large sample size ensured fair representation of students from diverse socio-economic backgrounds. The study could have overestimated the prevalence of STS due to data collection at public places within the university where a number of students might have keen interest in social gatherings.

In conclusion, the current study reported a high prevalence of current use of shisha among university students with a narrow gender gap, and STS is getting 
more popular than other forms of tobacco. Importantly, a substantial proportion of the students had low knowledge of STS harm with misconceptions about the harmful and addictive effects of STS, and a significant proportion of these students were current users of STS. Low risk-perception about STS and social acceptability were significantly contributed to the higher prevalence of STS among the youth. The findings of this study indicate an urgent need to promote multi-disciplinary health education activities for increasing awareness among different age groups in order to prevent youth from all type of smoking including shisha. Apart from creating the educational interventions, the Saudi higher authorities should have review and update regulations (i) to issue licenses for cafes and restaurants offering shisha, (ii) to replace misleading labels or descriptions such as ' $100 \%$ natural' with health warning labels on shisha devices/ products, and (iii) to limit the availability of flavoured tobacco products.

\section{Acknowledgments}

We thank Mr. Teyseer Abuhyzah, Mr. Redal AlRasheed, and Ms.Safial Almubudh for their support with the data collection. We also thank Dr. Syed Ghori for their support with the data management.

\section{References}

Aboaziza E, Eissenberg T (2015). Waterpipe tobacco smoking: what is the evidence that it supports nicotine/tobacco dependence?. Tob Control, 24, i44-53.

Abu-Rmeileh N, Alkhuffash O, Kheirallah K, et al (2018). Harm perceptions of waterpipe tobacco smoking among university students in five Eastern Mediterranean Region countries: A cross-sectional study. Tob Induc Dis, 16, doi:10.18332/ tid/89966.

Afifi R, Khalil J, Fouad F, et al (2013). Social norms and attitudes linked to waterpipe use in the Eastern Mediterranean Region. Soc Sci Med, 98, 125-34.

Akl EA, Ward KD, Bteddini D, et al (2015). The allure of the waterpipe: a narrative review of factors affecting the epidemic rise in waterpipe smoking among young persons globally. Tob Control, 24, 13-21.

Al Ghobain M, Ahmed A, Abdrabalnabi Z, et al (2018). Prevalence of and attitudes to waterpipe smoking among Saudi Arabian physicians. East Mediterr Heal J, 24, 277-82.

Al Moamary MS, Al Ghobain MA, Al Shehri SN, et al (2012). The prevalence and characteristics of water-pipe smoking among high school students in Saudi Arabia. J Infect Public Health, 5, 159-68.

Al Nomay NS, E Ahmed A (2015). Water Pipe use and the awareness of its effect on oral health in Riyadh, Saudi Arabia. J Oral Hyg Heal, 3, 1-5.

Algabbani AM, Almubark R, Althumiri N, et al (2018). The Prevalence of Cigarette smoking in Saudi Arabia in 2018. Food Drug Regul Sci J, 1, doi: 10.32868/rsj.v1i1.22.

Allen J, Butler DD (1993). Assessing the effects of donor knowledge and perceived risk on intentions to donate blood. $J$ Health Care Mark, 13, 26-33.

AlSwuailem AS, AlShehri MK, Al-Sadhan S (2014). Smoking among dental students at King Saud University: Consumption patterns and risk factors. Saudi Dent J, 26, 88-95.

Amin TT, Amr MAM, Zaza BO, Suleman W (2010). Harm perception, attitudes and predictors of waterpipe (shisha) smoking among secondary school adolescents in Al-Hassa, Saudi Arabia. Asian Pac J Cancer Prev, 11, 293-301.

Aslam H, Saleem S, German S, Qureshi W (2014). Harmful effects of shisha: literature review. Int Arch Med, 7, doi: 10.1186/1755-7682-7-16.

Awan KH, Alrshedan A, Al Kahtani M, Patil S (2016). Waterpipe smoking among health sciences university students: Knowledge, attitude and patterns of use. Saudi Dent J, 28, 189-93.

Centers for Disease Control and Prevention (2010). Global Tobacco Surveillance System Data. In: online. https://www. cdc.gov/tobacco/global/gtss/gtssdata/index.html. Accessed 14 Feb 2019.

Daradka H, Khabour O, Alzoubi K, et al (2019). Tobacco and waterpipe use among university students in Saudi Arabia: impact of tobacco sales ban. East Mediterr Heal J, 25, 111-8.

Drope J, Schluger NW, Cahn Z, et al (2018). The Tobacco Atlas. American Cancer Society and Vital Strategies, Atlanta, pp $28-52$.

Eissenberg T, Shihadeh A (2009). Waterpipe Tobacco and cigarette smoking: Direct comparison of toxicant exposure. Am J Prev Med, 37, 518-23.

Jaam M, Al-Marridi W, Fares H, et al (2016). Perception and intentions to quit among waterpipe smokers in Qatar: a crosssectional survey. Public Heal Action, 6, 38-43.

Jawad M, Charide R, Waziry R, et al (2018). The prevalence and trends of waterpipe tobacco smoking: A systematic review. PLoS One, 13, e0192191.

Jradi H, Al-Shehri A (2014). Knowledge about tobacco smoking among medical students in Saudi Arabia: Findings from three medical schools. J Epidemiol Glob Health, 4, 269-76.

Maziak W (2011). The global epidemic of waterpipe smoking. Addict Behav, 36, 1-5.

Maziak W, Jawad M, Jawad S, et al (2015a). Interventions for waterpipe smoking cessation. Cochrane Database Syst Rev, 7, doi: 10.1002/14651858.CD005549.pub3

Maziak W, Taleb Z Ben, Bahelah R, et al (2015b). The global epidemiology of waterpipe smoking. Tob Control, 24, 3-12.

Moradi-Lakeh M, El Bcheraoui C, Tuffaha M, et al (2015). Tobacco consumption in the Kingdom of Saudi Arabia, 2013: findings from a national survey. BMC Public Health, 15, 611.

Naeem Z (2011). Emerging trend of Waterpipe use in Saudi Arabia. Int J Health Sci (Qassim), 5, 5-6.

Primack BA, Carroll M V., Weiss PM, et al (2016). Systematic review and meta-analysis of Inhaled Toxicants from Waterpipe and cigarette smoking. Public Health Rep, 131, $76-85$.

Primack BA, Sidani J, Agarwal AA, et al (2008). Prevalence of and associations with Waterpipe Tobacco smoking among U.S. University students. Ann Behav Med, 36, 81-6.

Roohafza H, Heidari K, Alinia T, et al (2015). Smoking motivators are different among cigarette and waterpipe smokers: The results of ITUPP. J Epidemiol Glob Health, 5, 249-58.

Salloum RG, Abu-Rmeileh N, Hamadeh R, et al (2017). Policy-relevant context of Waterpipe Tobacco smoking among University students in six countries across the Eastern Mediterranean region: A qualitative study. Asian Pac J Cancer Prev, 18, 2533-40.

Taha AZ, Sabra AA, Al-Mustafa ZZ, et al (2010). Water pipe (shisha) smoking among male students of medical colleges in the eastern region of Saudi Arabia. Ann Saudi Med, 30, $222-6$.

Tucktuck M, Ghandour R, Abu-Rmeileh NME (2018). Waterpipe and cigarette tobacco smoking among Palestinian university students: a cross-sectional study. BMC Public Health, 18, 1. 
Waziry R, Jawad M, Ballout RA, et al (2016). The effects of waterpipe tobacco smoking on health outcomes: an updated systematic review and meta-analysis. Int $J$ Epidemiol, 46, $32-43$.

WHO Study Group on Tobacco Product Regulation (2015). Advisory note: waterpipe tobacco smoking: health effects, research needs and recommended actions by regulators, $2^{\text {nd }}$ edn. World Health Organization, Geneva.

World Health Organization (2015). WHO global report on trends in prevalence of tobacco smoking 2015. World Health Organization, Geneva.

\section{(2) $(1)$}

This work is licensed under a Creative Commons AttributionNon Commercial 4.0 International License. 